This document is the accepted manuscript version of the following article:

Roa, J. J., wheeler, J. M., Trifonov, T., Fargas, G., Mateo, A., Michler, J., \& Jiménez-Piqué, E. (2015). Deformation of polycrystalline TRIP stainless steel micropillars. Materials Science and Engineering A: Structural Materials: Properties, Microstructure and Processing, 647, 51-57. https://doi.org/10.1016/j.msea.2015.08.082

This manuscript version is made available under the CC-BY-NC-ND 4.0 1icense

http://creativecommons.org/licenses/by-nc-nd/4.0/

\title{
Deformation of polycrystalline TRIP stainless steel micropillars
}

\author{
J. J. Roa ${ }^{1,2, *}$, J. M. Wheeler ${ }^{3,4}$, T. Trifonov ${ }^{2}$, G. Fargas ${ }^{1,2}$, A. Mateo ${ }^{1,2}$, J. Michler ${ }^{3}$, \\ E. Jiménez-Piqué ${ }^{1,2}$
}

${ }^{1}$ CIEFMA-Departament de Ciència dels Materials i Enginyeria Metal-lúrgica, ETSEIB, Universitat Politècnica de Catalunya, 08028 Barcelona, Spain

${ }^{2}$ CRnE, Campus Diagonal Sud, Edifici C', Universitat Politècnica de Catalunya, 08028 Barcelona, Spain

${ }^{3}$ Empa, Swiss Federal Laboratories for Materials Science and Technology, Laboratory for Mechanics of Materials and Nanostructures, Feuerwerkstrasse 39, CH-3602 Thun, Switzerland

${ }^{4}$ ETH Zürich, Laboratory for Nanometallurgy, Department of Materials Science, VladimirPrelog-Weg 5, CH-8093 Zürich, Switzerland

* Corresponding author, e-mail: joan.josep.roa@upc.edu

\begin{abstract}
The deformation mechanisms of the metastable austenite phase of a transformation induced plasticity (TRIP) stainless steel, AISI 301LN, have been investigated by compression of multicrystalline micropillars of different crystallographic orientations, with particular attention on the strain-induced phase transformation from austenite to martensite. Intergranular shearing and twinning were observed to be the primary deformation mechanisms, with a predominant $\langle 122\rangle$ orientation developed in the austenitic phase, combined with limited planar slip within single grains of austenite. The phase transformation from austenite to $\varepsilon$ and $\alpha^{\prime}-$ martensite was clearly observed adjacent to the sheared regions using TEM-EBSD techniques. The $\varepsilon$-martensite phase was found to be preferentially located in the regions near the grain boundaries which experienced higher shear stresses during compression.
\end{abstract}

Keywords: Transformation induced plasticity; microcompression; micro-pillar; in-situ deformation; shear events; mechanical twinning.

\section{Introduction}

Metastable austenitic stainless steels display transformation induced plasticity (TRIP), where austenite transforms into martensite by strain, either during forming or under service loads. The plastic deformation of the austenite phase creates the defect structure, which then acts as nucleation sites for martensite formation [1,2]. The amount of induced martensite which forms during deformation depends on the stress, temperature 
and deformation rate [3], as well as the alloy composition [4,5,6]. Plastic deformation can induce two types of martensite: $\varepsilon$ and $\alpha$; whose crystallographic structures are hcp and bec, respectively [7].

Upon tension, the creation of microscopic shear bands promotes the phase transformation from $\gamma$-austenite to $\varepsilon$-martensite $[8,9,10,11]$. In the case of straininduced martensitic transformations, effects at the macroscopic scale, mainly in terms of deformation mechanisms, are complex and not yet well-understood due to the path dependence of plastic deformation. It is therefore often difficult to deconvolute the dislocation-driven plasticity from the transformation-driven plasticity. In this regard, plasticity at small scales has been attracting increasing attention, since it has been found that many mechanical properties at the micro- and nanometric length scale differ from those at the continuum scale $[12,13,14,15]$.

In the past decades, significant effort have been made to understand the underlying mechanisms responsible for the phase transformation in multiphase TRIP steels at micrometric length scales. One of the most used techniques is nanoindentation $[16,17,18,19]$, because it allows testing of site specific small volumes of material, such as single grains or even grain-boundaries. This technique has been employed to analyze plastic deformation and strengthening behavior that is controlled by crystalline defects such as dislocations, grain boundaries, and inclusions [20,21,22]. However, the deformation produced by nanoindentation is governed by a complex stress field under hydrostatic pressure, and the deformation mechanisms produced by this complex stress field may be different than those produced by uniaxial stress. Consequently, it is difficult to extract deformation parameters from nanoindentation data suitable for inclusion into numerical computer models, which require simple uniaxial stress-strain information.

Over the last few years, great advances have been made in understanding the mechanical behavior of materials at micron and submicron length scales using nanoindentation systems to compress micro-scale pillars produced by focused ion beam (FIB) machining. This microcompression technique [23] is a miniaturized version of the conventional uniaxial compression test and can directly yield engineering stress-strain behavior. However, microcompression of single crystalline specimens with diameters from $\sim 0.1$ to $20 \mu \mathrm{m}$ have revealed stress-strain responses quite different from what would be expected from macroscopic behavior [24,25,26,27,28,29]. This is now 
frequently attributed to geometric constraint of dislocation-mediated plasticity $[30,31,32]$ by several different mechanisms.

Table 1. Literature values of the yield stress $\left(\sigma_{\mathrm{ys}}\right)$ for several steels obtained through the micropillar compression technique, where DP: dual phase materials, TWIP: twining-induced plasticity, HSLA: highstrength low-alloy, ODS: oxide dispersion-strengthened steels, CDSS: cast duplex stainless steels, AHSS: advanced high strength steel, A: Austenite, F: Ferrite, M: Martensite, A/M: interface austenite/martensite, F/M: interfase ferrite/martensite, AS: as-sintered and T.T: thermal treatment [33-45].

\begin{tabular}{|c|c|c|c|c|c|}
\hline Material & Chemical composition (wt.\%) & Phase & б Pillar $(\mu \mathrm{m})$ & $\sigma_{\mathrm{ys}}(\mathrm{MPa})$ & Ref. \\
\hline \multirow[t]{9}{*}{$\mathrm{DP}$} & \multirow{3}{*}{$0.15 \mathrm{C}-1.45 \mathrm{Mn}-0.30 \mathrm{Si}$} & $\mathrm{F}$ & \multirow{3}{*}{$1-2$} & $220-550$ & \multirow{3}{*}{33} \\
\hline & & $\mathrm{M}$ & & $1000-2500$ & \\
\hline & & F/M & & $500-600$ & \\
\hline & \multirow[t]{4}{*}{$0.013 \mathrm{C}-0.07 \mathrm{Mn}-0.83 \mathrm{Si}$} & $\mathrm{F}, \mathrm{AS}$ & \multirow[t]{4}{*}{1.5} & $569 \pm 8$ & \multirow[t]{4}{*}{34} \\
\hline & & M,AS & & $887 \pm 53$ & \\
\hline & & $\mathrm{F}\left(\mathrm{T} . \mathrm{T}=538^{\circ} \mathrm{C}\right)$ & & $610 \pm 151$ & \\
\hline & & $\mathrm{M}\left(\mathrm{T} . \mathrm{T}=538^{\circ} \mathrm{C}\right)$ & & $1177 \pm 54$ & \\
\hline & \multirow[t]{2}{*}{$0.09 \mathrm{C}-2.15 \mathrm{Mn}-0.60 \mathrm{Si}$} & F & $0.3-2$ & $220-450$ & \multirow[t]{2}{*}{35} \\
\hline & & $\mathrm{M}$ & $0.36-1.30$ & $1500-2500$ & \\
\hline M190 & $0.18 \mathrm{C}-0.47 \mathrm{Mn}-0.18 \mathrm{Si}$ & $\mathrm{M}$ & $>1^{*}$ & $1200-1400$ & 36 \\
\hline TWIP & $22 \mathrm{Mn}-0.6 \mathrm{C}$ & A & 3.9 & 1040 & 37 \\
\hline \multirow{2}{*}{$42 \mathrm{SiCr}$} & \multirow{2}{*}{$0.43 \mathrm{C}-0.59 \mathrm{Mn}-2 \mathrm{Si}-1.33 \mathrm{Cr}$} & $\mathrm{A}(\mathrm{Q}-\mathrm{P})$ & \multirow[t]{2}{*}{$3^{* *}$} & $1448 \pm 77$ & \multirow[t]{2}{*}{38} \\
\hline & & $\mathrm{A}(\mathrm{Q}-\mathrm{P}+\mathrm{TT})$ & & $1705 \pm 196$ & \\
\hline \multirow[t]{2}{*}{ AISI 316L } & \multirow[t]{2}{*}{-} & \multirow[t]{2}{*}{ A } & 5 & \multirow[t]{2}{*}{$\approx 380$} & \multirow[t]{2}{*}{39} \\
\hline & & & 15 & & \\
\hline \multirow[t]{2}{*}{ F70 forged steel } & \multirow[t]{2}{*}{$0.07 \mathrm{C}-0.60 \mathrm{Mn}-0.25 \mathrm{Si}-0.79 \mathrm{Cr}$} & \multirow[t]{2}{*}{$\mathrm{A} / \mathrm{M}$} & 0.25 & 3000 & \multirow[t]{2}{*}{40} \\
\hline & & & 0.9 & 1200 & \\
\hline \multirow[t]{2}{*}{ HSLA } & \multirow[t]{2}{*}{$0.09 \mathrm{C}-1.54 \mathrm{Mn}-0.19 \mathrm{Si}$} & \multirow[t]{2}{*}{$\mathrm{A} / \mathrm{M}$} & 1 & $750-950$ & \multirow[t]{2}{*}{41} \\
\hline & & & 3 & $750-1150$ & \\
\hline ODS ferritic steel & $15 \mathrm{Cr}-2 \mathrm{~W}-0.2 \mathrm{Ti}-0.35 \mathrm{Y}_{2} \mathrm{O}_{3}$ & F & $1-7.4$ & $\approx 1000-1100$ & 42 \\
\hline \multirow[t]{7}{*}{ CDSS } & \multirow[t]{7}{*}{$20.99 \mathrm{Cr}-9.07 \mathrm{Ni}-0.76 \mathrm{Mn}-0.92 \mathrm{Si}^{* * *}$} & A & \multirow[t]{2}{*}{1} & $\approx 630$ & \multirow[t]{7}{*}{43} \\
\hline & & F & & $\approx 830$ & \\
\hline & & A & 2 & $\approx 680$ & \\
\hline & & $\mathrm{F}$ & & $\approx 500$ & \\
\hline & & A & 5 & $\approx 330$ & \\
\hline & & $\mathrm{F}$ & & $\approx 580$ & \\
\hline & & $\mathrm{A}$ & 10 & $\approx 300$ & \\
\hline Metastable austenitic & $0.0013 \mathrm{C}-8.14 \mathrm{Ni}-10.3 \mathrm{Cr}-7.41 \mathrm{Mn}$ & $\mathrm{A}\left(\mathrm{T} . \mathrm{T}=575^{\circ} \mathrm{C}\right)$ & $0.6-18$ & $\approx 750-900$ & 44 \\
\hline & & $\mathrm{A}\left(\mathrm{T} . \mathrm{T}=615^{\circ} \mathrm{C}\right)$ & & $\approx 450-700$ & \\
\hline AHSS & $0.2 \mathrm{C}-1.5 \mathrm{Si}-1.8 \mathrm{Mn}-0.02 \mathrm{P}-0.05 \mathrm{Al}$ & F & $1-1.6$ & $500-600$ & 45 \\
\hline & & $\mathrm{M}$ & & $800-1000$ & \\
\hline
\end{tabular}

* Diameters greater than $1 \mu \mathrm{m}$, the flow stress is independent of the pillar diameter.

** Denotes square pillars

*** Chemical composition in at.\%

Q-P denotes quenching and partitioning process, while Q-P+TT refers to the Q-P process plus thermal treatment.

Several recent studies $[46,47,48,49,50]$ have applied the micropillar compression technique to investigate the small scale behavior of steel alloys. A summary of the chemical compositions, constitutive phases, and yield stresses $\left(\sigma_{\mathrm{ys}}\right)$ of the various steels investigated by these studies is given in Table 1. In the majority of these studies, the testing was performed within single grains and unique phases. Little information is available within the literature on the behavior of pillars containing multiple phases and/or grain boundaries.

The deformation behavior of polycrystalline micropillars is critical for determining the role of grain boundaries in the deformation and transformation mechanisms to increase the accuracy of microstructure-based simulations [50]. Here, the deformation 
mechanisms of TRIP stainless steels are investigated by microcompression of multicrystalline pillars containing a few grain boundaries. The resulting phase transformations and deformation mechanisms activated during the compression are then studied using scanning electron microscopy (SEM) and transmission electron microscopy (TEM).

\section{Experimental procedure}

The material investigated in this work is a commercial AISI 301LN stainless steel, equivalent to EN 1.4318, supplied by Outokumpu (Finland) as $2 \mathrm{~mm}$ thick sheets with an initial percentage of martensite of $8 \pm 1 \%$. Mean grain size was measured following the linear intercept method on micrographs taken with a field emission scanning electron microscope (FESEM), resulting in a grain size of $40 \pm 5 \mu \mathrm{m}$. Its chemical composition is given in Table 2.

Table 2. Chemical composition of the studied stainless steel AISI 301LN (wt\%).

\begin{tabular}{|l|l|l|l|l|l|l|}
\hline $\mathbf{C}$ & $\mathbf{C r}$ & $\mathbf{N i}$ & $\mathbf{M n}$ & $\mathbf{S i}$ & $\mathbf{M o}$ & $\mathbf{N}$ \\
\hline 0.02 & 17.48 & 7.03 & 1.23 & 0.45 & 0.12 & 0.12 \\
\hline
\end{tabular}

The as-received material was ground with silicon carbide and then polished with diamond suspension of 30, 6 and $3 \mu \mathrm{m}$. Finally, a neutral suspension of $20 \mathrm{~nm}$ alumina particles was used as a final polish to remove any possible surface damage during previous surface preparation steps.

After that, micropillars were produced using a dual beam Zeiss Neon 40 focused ion beam - field emission scanning electron microscope (FIB/FESEM) with a $\mathrm{Ga}^{+}$ion source operated at $30 \mathrm{kV}$. The milling process was carried out in several stages using decreasing ion beam currents down to $500 \mathrm{pA}$ to produce micropillars with diameters from 2 to $3 \mu \mathrm{m}$ and aspect ratios ranging from 3 to 5 . The resulting pillars presented a taper angle of approximately $2-3^{\circ}$. This is typical for pillars produced using annular milling $[51,52,53]$ and is attributed to the profile of the ion beam, ion scattering effects, and redeposition of sputtered material. Table 3 summarizes the dimensions (diameter, length and aspect ratio) and nomenclature of the micropillars. 
Table 3. Label, diameter $(D)$, length $(L)$ and ratio $L / D$ for the TRIP steel micropillars.

\begin{tabular}{|c|c|c|c|}
\hline Label & Diameter, $D(\mu \mathrm{m})$ & Length, $L(\mu \mathrm{m})$ & $L / D(-)$ \\
\hline $\mathrm{P} 1-2 \mu \mathrm{m}$ & 2.2 & 11.2 & 5.0 \\
\hline P2-2 $\mu \mathrm{m}$ & 2.1 & 10.9 & 5.2 \\
\hline $\mathrm{P} 3-2 \mu \mathrm{m}$ & 2.2 & 10.3 & 4.7 \\
\hline $\mathrm{P} 4-2 \mu \mathrm{m}$ & 2.1 & 10.2 & 4.9 \\
\hline $\mathrm{P} 1-3 \mu \mathrm{m}$ & 2.7 & 11.2 & 4.2 \\
\hline $\mathrm{P} 2-3 \mu \mathrm{m}$ & 3.1 & 10.9 & 3.5 \\
\hline $\mathrm{P} 3-3 \mu \mathrm{m}$ & 3.3 & 10.7 & 3.2 \\
\hline $\mathrm{P} 4-3 \mu \mathrm{m}$ & 3.3 & 10.6 & 3.2 \\
\hline
\end{tabular}

The crystallographic orientation of the tops of the pillars was determined by electron back-scattered diffraction (EBSD) using a JEOL 7001F equipped with an orientation imaging microscopy system and with a constant scanning step (50 nm), at an acceleration voltage of $20 \mathrm{kV}$.

In-situ microcompression tests were carried out using an Alemnis SEM Indenter [52,54], which is intrinsically displacement controlled, within a Zeiss DSM962 SEM. Micropillars were compressed at a constant displacement rate appropriate to generate a strain rate of $10^{-3} \mathrm{~s}^{-1}$. Engineering stress-strain curves were determined from the load $(P)$ vs. displacement $(h)$ curves, using the top diameter of the pillars after correcting for pillar sink-in and instrument compliance [52].

The microstructure of selected zones of the deformed pillars was characterized using FIB serial cross-sectioning at ion beam currents of $500 \mathrm{pA}$ to obtain a detailed characterization of the internal damage. Milling of more than 500 slices was performed to obtain a high resolution $3 \mathrm{D}$ analysis. The resulting $3 \mathrm{D}$ reconstruction was performed using AVIZO 8.0 software.

A lamella for transmission electron microscopy (TEM) was extracted by FIB from the center of one of the deformed pillars, with current and acceleration voltage decreased down to a final polishing stage at $30 \mathrm{kV}$ and $10 \mathrm{pA}$. FIB-induced amorphization of the surface of the lamella was reduced by a short final milling step with the ion beam at 5 $\mathrm{kV}$ and $10 \mathrm{pA}$. Deformation features within the FIB-milled lamellae were examined in a scanning transmission electron microscope (STEM) coupled with the Zeiss Neon 40 unit. The local crystallographic orientations and phases of the deformed pillars were assessed by means of EBSD coupled to a JEOL JEM 2100 TEM operating at $200 \mathrm{kV}$. This microscope uses the precession electron diffraction (PED) device $[55,56]$ 
ASTAR/DigiSTAR from NanoMEGAS for crystal orientation mapping, which is described in detail elsewhere [57].

\section{Results and discussion}

Two sets of pillars with different diameter $(2$ and $3 \mu \mathrm{m})$ were milled in the grain boundaries between different austenitic grains. The local crystallographic orientation of the top surface of each pillar of interest is depicted in Figure 1a. Grain boundaries are observed either to intersect the top surfaces or transect the lower gage region of the pillars. The main crystallographic orientations for each micropillar were determined through Euler angles by electron diffraction, see Table 4. Phase orientation analysis confirmed, as it was referred above, that micropillars present an austenitic microstructure before the deformation, see Figure $\mathbf{1 b}$.

Table 4. Crystallographic orientations for each grain present inside of each micropillar in the contact region directly determined through the Euler angles by means of EBSD as well as their fraction.

\begin{tabular}{|c|c|c|}
\hline Label & Crystallographic orientation, $\langle h k l\rangle$ & Fraction (\%) \\
\hline \multirow[t]{4}{*}{$\mathrm{P} 1-2 \mu \mathrm{m}$} & $\langle 113\rangle$ & 41.4 \\
\hline & $\langle 222\rangle$ & 2.6 \\
\hline & $\langle 002\rangle$ & 1.5 \\
\hline & Non-indexed & 54.5 \\
\hline \multirow[t]{3}{*}{$\mathrm{P} 2-2 \mu \mathrm{m}$} & $\langle 122\rangle$ & 58.9 \\
\hline & $\langle 212\rangle$ & 23.4 \\
\hline & Non-indexed & 17.7 \\
\hline \multirow{3}{*}{ P3-2 $2 \mu \mathrm{m}$} & $\langle 122\rangle$ & 79.4 \\
\hline & $\langle 003\rangle$ & 2.1 \\
\hline & Non-indexed & 18.4 \\
\hline \multirow[t]{4}{*}{$\mathrm{P} 4-2 \mu \mathrm{m}$} & $\langle 113\rangle$ & 34.1 \\
\hline & $\langle 002\rangle$ & 14.4 \\
\hline & $\langle 013\rangle$ & 11.8 \\
\hline & Non-indexed & 39.7 \\
\hline \multirow[t]{2}{*}{$\mathrm{P} 1-3 \mu \mathrm{m}$} & $\langle 122\rangle$ & 77.2 \\
\hline & Non-indexed & 22.8 \\
\hline \multirow[t]{3}{*}{$\mathrm{P} 2-3 \mu \mathrm{m}$} & $\langle 222\rangle$ & 26.6 \\
\hline & $\langle 122\rangle$ & 2.6 \\
\hline & Non-indexed & 70.8 \\
\hline \multirow[t]{4}{*}{$\mathrm{P} 3-3 \mu \mathrm{m}$} & $\langle 212\rangle$ & 26.8 \\
\hline & $\langle 202\rangle$ & 23.2 \\
\hline & $\langle 003\rangle$ & 4.9 \\
\hline & Non-indexed & 45.1 \\
\hline \multirow[t]{2}{*}{$\mathrm{P} 4-3 \mu \mathrm{m}$} & $\langle 122\rangle$ & 74.7 \\
\hline & Non-indexed & 25.3 \\
\hline
\end{tabular}

Engineering stress-strain curves for austenite micropillars are shown in Figure 2a and

2b for the two different diameters, i.e., 2 and $3 \mu \mathrm{m}$. The scatter in the stress-strain 
curves is large and may be attributed to the variation in crystallographic orientation and grain structure within the pillars. The pillars were milled targeting grain boundaries. However, this is only achieved for the pillar top surface, since the lower parts of the pillar length may contain additional grain boundaries and grains with different crystallographic orientations. Several of the stress-strain curves display inflections followed by work-hardening. This was observed in-situ during compression to coincide with a large shear or slip event occurring within the gage of the pillar. This phenomenon may be related to martensitic transformation $\left(\gamma \rightarrow \alpha^{\prime}\right)$ [58], which causes volume changes during the test, similarly to what is observed in macroscopic tests.

From the data summarized in Table 5 and plotted in Figure 2, the role of the sample size on the mechanical properties determined from the stress-strain curve is unclear, since the range of sizes investigated is quite narrow. Additionally, the significant crystallographic variation between pillars makes comparisons between the two sizes difficult, but on average the smaller pillars are observed to be slightly stronger. This behavior is in disagreement with Ghassemi-Armaki and co-workers [33], who reported that for martensitic pillars with diameters greater than $1 \mu \mathrm{m}$, the flow stress is independent of the pillar diameter. In their case, the intrinsic size effect due to the fine structure of the martensite likely overwhelmed the effect of extrinsic dimensional constraint of the pillar diameter in larger pillars. The yield stresses of the submicronsized pillars tested here ranges from 630 to $1500 \mathrm{MPa}$, whereas for conventional bulk steel specimens a value of $670 \mathrm{MPa}$ was measured [59]. The origin of the higher yield stress for pillars could be related to the size-effect phenomenon $[60,61]$, where the yield stress is increased in submicron pillars due to the truncation of and limited availability of dislocation sources. Also, this phenomenon can be related to accumulation of dislocations at the grain boundary, as reported by $\mathrm{Ng}$ and Ngan [62] in bi-crystal $\mathrm{Al}$ micropillars. In steel pillars, increased strengths might also be attributed to the generation of martensite during compression. Since the yield stresses reported here are similar to values reported for the pure martensitic phase in other steels (see Table 1), this explanation seems plausible.

Table 5. Yield strength $\left(\sigma_{y}\right)$ and total deformation (TD).

\begin{tabular}{|l|l|l|}
\hline Label & $\sigma_{\boldsymbol{v}}(\mathbf{G P a})$ & TD $(\%)$ \\
\hline $\mathrm{P} 1-2 \mu \mathrm{m}$ & 1.50 & 15.0 \\
\hline $\mathrm{P} 2-2 \mu \mathrm{m}$ & 1.21 & 11.1 \\
\hline $\mathrm{P} 3-2 \mu \mathrm{m}$ & 1.25 & 13.1 \\
\hline
\end{tabular}




\begin{tabular}{|l|l|l|}
\hline $\mathrm{P} 4-2 \mu \mathrm{m}$ & 1.17 & 9.9 \\
\hline $\mathrm{P} 1-3 \mu \mathrm{m}$ & 1.13 & 5.3 \\
\hline $\mathrm{P} 2-3 \mu \mathrm{m}$ & 0.87 & 11.6 \\
\hline $\mathrm{P} 3-3 \mu \mathrm{m}$ & 1.41 & 12.6 \\
\hline $\mathrm{P} 4-3 \mu \mathrm{m}$ & 0.63 & 9.90 \\
\hline
\end{tabular}

FESEM micrographs of representative pillars (before and after deformation) are shown in Figure 3. Deformation is observed to occur primarily by intergranular sliding with a limited amount of crystallographic slip.

Figure 4 presents close-up views of three different pillars after deformation. In these FESEM images, small slip offsets can be appreciated at the surface marking the exit of dislocations from a slip plane within a single crystal. However, most pillars exhibited large shear offsets (Figures $\mathbf{4 a}$ and $\mathbf{4 c}$ ), which could be attributed to shearing of the grain boundaries. This is an expected result, since pillars contained grain boundaries which were not oriented parallel to the loading direction. Neither concentrated slip bands nor buckling were observed in pillars of either of the tested sizes. However, the pillar shown in Figure $\mathbf{4 b}$ does not display any shear offsets along a grain boundary, highlighting that other deformation mechanisms can control the plasticity of metastable steels under pillar compression.

In order to visualize the deformation inside one of the pillars, micropillar P2-3 $\mu \mathrm{m}$ was sequentially cross-sectioned and imaged using the FIB/FESEM system. A secondary electron micrograph of the deformed microstructure from a central slice is shown in Figure 5. Significant shear offsets can be seen to coincide with the grain boundaries around the central large darker grain. Within the upper and lower regions, a complicated microstructure can already be observed without TEM. A glide system at the interface between two austenitic grains at an angle of about $45^{\circ}$ from the compression axis can be seen in the full tomographic reconstruction (see supplementary material for sequential cross-sectioning of the same pillar presented in Figure 5).

The serial sectioning technique is useful for visualizing the deformation within the entire volume of the micropillar, but it lacks quantitative structural information on the deformed regions. Figure 6a shows bright field STEM (BF-STEM) micrographs of the cross-section of pillar P1-3 $\mathrm{m}$, which was deformed by approximately $5.3 \%$. In the overall micrograph at the left hand side of the figure, two different deformation mechanisms can be observed: intergranular shearing and deformation twinning. In the bottom part of the pillar, a fine-grained microstructure can be observed, as well as a dense dislocation forest. In the magnified region, presented at the right side, 
deformation twins with thicknesses of $400-500 \mathrm{~nm}$ can be observed. These mechanical twins can be associated with Shockley partials gliding on successive $\{111\}$ planes [63]. These deformation effects can partly account for the shear band and martensite phase formation. Development of those deformation mechanisms are related to the stacking fault energy and crystallographic orientation according to the indentation axis. The austenitic character of these deformation twins presented in figure 6a was corroborated through analysis of selected-area electron diffraction (SAED) patterns, pointing then out that this defect is mechanical twins. Figure 6b represents the SAED taken from the circled area presented in the BF-STEM image.

Figure 7a illustrates BF-STEM micrograph of another pillar (P4-3 $\mu \mathrm{m})$, where the same deformation mechanisms seen in Figure 6 are observed in the upper region of the pillar. Furthermore, the shear bands extending through the austenitic pillars in Figures 6 and 7a correspond to the situation where the stacking faults become unstable and diverge due to the applied stress, as predicted by Byun's model [64]. EBSD-TEM analysis presented in Figure 7b reveals the phases in the different deformed regions. Since the austenite grains in contact with the indenter experience intergranular shearing, the residual stresses near grain boundary may induce phase transformations. Figure $\mathbf{7 b}$ illustrates that both the $\alpha^{\prime}$ and $\varepsilon$-martensite transformed regions are located adjacent to the grain boundaries, where significant shear strains are observed. The total amount of martensite ( $\alpha$, and $\varepsilon$-martensite) induced during the micropillar compression in the central part for the $\mathrm{P} 3-3 \mu \mathrm{m}$ is around $10 \%$ directly calculated from Figure 7. This implies that $\alpha^{\prime}$-martensite transformation occurred concurrently with $\varepsilon$-martensite, which is in agreement with some previous observations $[65,66]$. Nevertheless, $\alpha^{\prime}$ was observed primarily at dislocation pile-ups, as noted previously [67], whereas $\varepsilon$ martensite is mainly observed in the highly sheared zones near the grain boundaries. Other authors $[68,69,70]$ have suggested that $\alpha^{\prime}$ formation should take place without the presence of $\varepsilon$-martensite, which is not the mechanism observed under the studied conditions.

\section{Conclusions}

From the analysis of the experimental results obtained in this investigation, the following conclusions may be drawn: 
- The yield stress values determined from the stress-strain curves are higher than the values for austenitic phase obtained from micropillar compression for other steel grades due to the presence of transformation induced martensitic phase in the grain boundaries.

- Plastic deformation during the micropillars compression of metastable stainless steels was accommodated primarily through grain boundary sliding, but planar slip and mechanical twinning were also observed.

- Both types of martensite, $\alpha^{\prime}$ and $\varepsilon$, form in metastable stainless steel after pillar compression.

- Deformation-induced phase transformations were observed using TEM to be associated with two different processes: dislocation pile-ups for the $\alpha^{\prime}$ martensite and shear strain for the $\varepsilon$-martensite.

\section{Acknowledgements}

The authors greatly acknowledge I. López Insa from the "Laboratori de Microscopia Electrònica del CMEM-UPC" and J. Portillo from the "Scientific-technical Services, University of Barcelona" for their contribution to the EBSD and TEM-EBSD image analysis, respectively. We are grateful to "Direcció General de Recerca del Comissionat per a Universitats i Recerca de la Generalitat de Catalunya" for recognizing CIEFMA as consolidate Research Group (2014-SGR-130), and also to J. Säynäjäkangas and A. Kalapudas from Outokumpu (Finland) for supplying the stainless steel sheets. Dr. J. J. Roa would like to thank the Juan de la Cierva Programme for its financial support (grant number: JCI-2012-14454).

\section{References}

[1] S. Rajasekhara, P. J. Ferreira, L. P. Karjalainen, A. Kyröläinen, Metall. Mater. Trans. A. 38A (2007) 1202-1210.

[2] J. B. Vogt, Z. Magnin, J. Foct, Fract. Eng. Mater. Struct. 16 (1993) 555-564.

[3] H. F. G. Abreu, M. J. G. da Silva, L. F. G. Herculano, H. Bhadeshia, Mater. Res. 12 (2009) 291-297.

[4] A. D. Schimo, M. Barteri, J. M. Kenny, J. Mater. Sci. Lett. 21 (2002) 751-753.

[5] J. Y. Choi, W. Jin, Scr. Mater. 36 (1997) 99-104. 
[6] E-Y. Guo, H-X Xie, S. S. Singh, A. Kirubanandham, T. Jing, N. Chawla, Mater. Sci. Eng. A. 598 (2014) 98-105.

[7] H. F. G. de Abreu, S. S. de Carvalho, P. L. Neto, R. P. dos Santos, V. N. Freire, P. M. O. Silva, S. S. M. Tavares, Mater. Res. 10 (2007) 359-366.

[8] S. S. Hecker, M. Sotut, K. Staudhammer, J. Smith. Metall. Mat. Trans. A 13 (1982) 619-626.

[9] L. E. Murr, K. Staudhammer, S. Hecker, Metall. Mat. Trans. A 13 (1982) 627-635.

[10] S. G. S. Taman, K. A. Padmanabhan, J. Mater. Sci. Lett. 13 (1994) 389-392.

[11] J. Talomen, P. Nenonen, G. Pape, H. Hänninen, Metall. Mat. Trans. A 36 (2005) 421-432.

[12] S. Brinckmann, J. -Y. Kim, J. R. Greer, Phys. Rev. Lett. 100 (2008) 15502.

[13] D. Kiener, W. Grosinger, G. Dehm, R. Pippan, Acta Mater. 56 (2008) 580-592.

[14] M. D. Uchic, D. M. Dimiduk, J. N. Florando, W. D. Nix, Science. 305 (2004) 986989.

[15] S. H. Oh, M. Legros, D. Kiener, G. Dehm, Nat. Mater. 8 (2009) 95-100.

[16] R. D. K. Misra, Z. Zhang, Z. Jia, M. C. Somani, L. P. Karjalainen, Scrip. Mater. 63 (2010) 1057-1060.

[17] Q. Furnémont, M. Kempf, P. J. Jacques, M. Go, Mat. Sci. Eng A 328 (2002) 26-32.

[18] P.S.S. Leung, A. H. W. Ngan, Scrip. Mater. 69 (2013) 235-238.

[19] T. H. Ahn, C. S. Oh, D. H. Kim, K. H. Oh, H. Bei, E. P. George, H. N. Han, Scripta. Mater. 63 (2010) 540-543.

[20] J. -I. Jang, S. Shim, S. -I. Komazaki, T. Honda, J. Mater. Res. 22 (2007) 175-185.

[21] B. -W. Choi, D. -H. Seo, J. -Y. Yoo, J. -I. Yang, J. Mater. Res. 24 (2009) 816822.

[22] L. Zhang, T. Ohmure, A. Shibate, K. Tsuzaki, Mater. Sci. Eng. A. 527 (2010) 1869-1874.

[23] M. D. Uchic, D. A. Dimiduk, Mater. Sci. Eng. A. 268 (2005) 400-401.

[24] M. D. Uchic, D. M. Dimiduk, J. N. Florando, W. D. Nix, Science. 305 (2004) 986989.

[25] J. L. Stewart, L. Jiang, J. J. Williams, N. Chawla, Mater. Sci. Eng. A. 534 (2012); 220-227.

[26] D. R. P. Singh, N. Chawla, G. Tang, Y. -L. Shen, Acta Mater. 58 (2010) 6628-636.

[27] L. Jiang, N. Chawla, Scrip. Mater. 63 (2010) 480-483. 
[28] J. R. Greer, W. C. Oliver, W. D. Nix, Acta Mater. 53 (2005) 1821-1830.

[29] J. J. Williams, J. L. Walters, M. Y. Wang, N. Chawla, A. Rohatgi, JOM. 65 (2013); 226-233.

[30] M. D. Uchic, P. A. Shade, D. M. Dimiduk, Ann. Rev. Mater. Res. 39 (2009) 361386.

[31] O. Kraft, P. A. Gruber, R. Mönig, D. Weygand, Ann. Rev. Mater. Res. 40 (2010) 293-317.

[32] J. R. Greer, J. T. M. De Hosson, Prog. Mat. Sci. 56 (2011) 654-724.

[33] H. Ghassemi-Armaki, R. Maab, S. P. Bhat, S. Sriram, J. R. Greer, K. S. Kumar, Acta Mater. 62 (2014) 197-211.

[34] J. L. Stewart, L. Jiang, J. J. Williams, N. Chawla, Mat. Sci. Eng. A. 534 (2012) 220-227.

[35] P. Chen, H. Ghassemi-Armaki, S. Kumar, A. Bower, S. Bhat, S. Sadagopan, Acta Mater. 65 (2014) 133-149.

[36] H. Ghassemi-Armaki, P. Chen, S. Bhat, S. Sadagopan, S. Kumar, A. Bower, Acta Mater. 61 (2013) 3640-3652.

[37] S. Z. Wu, H. W. Yen, M. X. Huang, A. H. W. Ngan, Scripta Mater. 67 (2012) 641644.

[38] H. Jirková, B. Masek, M. F. -X. Wagner, D. Langmajerová, L. Kucerová, R. Treml, D. Kiener, J.All.Comp. 615 (2014) S163-S168.

[39] G. Monnet, M. A. Pouchon, Mat. Lett. 98 (2013) 128-130.

[40] V. G. Haugen, B. R. S. Rogne, O. M. Akselsen, C. Thaulow, E. Ostby, Mat. Design. 59 (2014) 135-140.

[41] B. R. S. Rogne, C. Thaulow, A. Barnoush, Metal. Met. Trans. A. 45A (2014) 19962003.

[42] C. Shin, S. Lim, H. -Ha Jin, P. Hosemann, J. Kwon, J. Nucl. Mat. 444 (2014) 4348.

[43] E. -Y. Guo, H. -X. Xie, S. S. Singh, A. Kirubanandham, T.Jing, N.Chawla, Mat. Sci. Eng. A. 598 (2014) 98-105.

[44] C. Shin, S. Lim, H. -Ha Jin, P. Hosemann, J. Kwon, Mat. Sci. Eng. A. 622 (2015) $67-75$.

[45] A. Srivastava, H. Ghassemi-Armaki, H. Sung, P. Chen, S. Kumar, A. F. Bower, J. Mech. Phys. Sol. 78 (2015) 46-69. 
[46] S. Z. Wu, H. W. Yen, M. X. Huang, A. H. W. Ngan, Scripta Mater. 67 (2012) 641644.

[47] H. Ghassemi-Armaki, R. Maa $\beta$, S. P. Bhat, S. Sriram, J. R. Greer, K. S. Kumar, Acta Mater. 62 (2013) 197-211.

[48] J. L. Stewart, L. Jiang, J. J. Williams, N. Chawla, Mat. Sci. Eng. A 534 (2012) 220227.

[49] G. Monnet, M. A. Pouchon, Mater. Lett. 98 (2013) 128-130.

[50] H. Ghassemi-Armaki, P. Chen, S. Bhat, S. Sadagopan, S. Kumar, A. Bower, Acta Mater. 61 (2013) 3640-3652.

[51] C. Marichal, H. Van Swygenhoven, S. Van Petegem, C. Borca, Sci Report. 3 (2013) 1-7.

[52] J. M. Wheeler, J. Michler, Rev. Sci. Instrum. 84 (2013) 045103/1-045103/15.

[53] H. Zhang, B. E. Schuster, Q. Wei, K. T. Ramesh, Scr. Mater. 54 (2006) 181-186.

[54] R. Rabe, J.M. Breguet, P.Schwaller, S.Strauss, F.J. Haug, J.Patscheider, J. Michler, Thin Solid Films 469 (2004) 206-213.

[55] R. Vincent, P. Midgley, Ultram. 53 (1994) 271-282.

[56] A. Avilov, K. Kuligin, S. Nicolopoulos, M. Nickolskiy, K. Boulahya, J. Portillo, G. Lepeshov, B. Sobolev, J. P. Collette, N. Martin, A. C. Robins, P. Fischione, Ultram. 107 (2007) 431-444.

[57] P. Moeck, S. Rouvimov, E. F. Rauch, M. Véron, H. Kirmse, I. Häusler, W. Neumann, D. Bultreys, Y. Maniette, S. Nicolopoulos, Cryst. Res. Technol. 46 (2011) 589-606.

[58] J. Bouquerel, K. Verbeken, B. C. Cooman, Acta Mater. 54 (2006) 1443-1456.

[59] J. J. Roa, G. Fargas, E. Jiménez-Piqué, A. Mateo, Mat. Sci. Eng. A. 597 (2014) 232-236.

[60] J. R. Greer, J. T. M. De Hosson, Prog. Mater. Sci. 56 (2011) 654-724.

[61] Y. -J. Kim, K. Son, I. -C. Choi, I. -S. Choi, W. I. Park, J. -I. Jang, Adv. Funct. Mater. 21 (2011) 279-286.

[62] K. S. Ng, A. H. W. Ngan, Philos. Mag. 89 (2009) 3013-3026.

[63] P. J. Ferreira, J. B. Vander Sande, A. Fortes, A. Kyroläinen, Metall. Mater. Trans. A 35 (2004) 3091-3101.

[64] T. S. Byun, Acta Mater. 51 (2003) 3063-3071.

[65] W. -S. Lee, C. -F. Lin, Script. Mater. 43 (2000) 777-782. 
[66] N. Gey, B. Petit, M. Humber, Metall. Mat. Trans. A 36 (2005) 3291-3299.

[67] J. W. Brooks, M. H. Loretto, R. E. Smallman, Acta Metall. 27 (1979) 1829-1838.

[68] T. Narutani, G. B. Olson, M. Cohen, J. Phys. 43 (1982) 429-434.

[69] T. Narutani, Mat. Trans. 30 (1989) 33-45.

[70] J. A. Lichtenfeld, M. C. Mataya, C. J. Tyne, Metall. Mat. Trans. A 37 (2006) 147161. 